\title{
AC 2012-4189: BEING INNOVATIVE: LESSONS LEARNED FROM THE PRACTICE OF TECHNOLOGY COMMERCIALIZATION
}

Dr. William A Kline, Rose-Hulman Institute of Technology

Bill Kline is professor of engineering management and is currently serving as interim Dean of the Faculty at Rose-Hulman Institute of Technology. Kline has a Ph.D. degree from the University of Illinois in mechanical engineering and worked in industry for many years before joining Rose-Hulman. Kline was Co-founder and Chief Technical Officer at Montronix, a company providing monitoring systems for industrial machinery. At Rose-Hulman, his professional interests include design, innovation, systems engineering, quality, and manufacturing systems.

\section{Dr. Thomas W. Mason, Rose-Hulman Institute of Technology}

Tom Mason is Professor Emeritus of economics and engineering management at Rose-Hulman Institute of Technology, where he has been teaching since 1972. He was founding Head of the Engineering Management Department and its M.S. degree program and founding Vice President for Entrepreneurship \& Business Planning of Rose-Hulman Ventures and has also served Rose-Hulman as Head of Humanities and Social Sciences, Vice-President for Administration and Finance, Head of Engineering Management, and Interim Vice President for Development. While on a three-year leave from Rose-Hulman, Mason served as CFO and CEO of a 140-person network management systems business. In 2007-08, he used his sabbatical to study entrepreneurship in Indiana and assist start-ups as Educator/Entrepreneur in Residence at Indiana Venture Center. He has been Advisor/Director for several high tech firms and has been involved in national efforts to integrate entrepreneurship and engineering education. Since his retirement from full-time teaching, Mason has co-authored an updated edition of Forecasting and Management of Technology, teaches part-time, continues his research and writing on innovation and entrepreneurship, and works in an advisory capacity with several emerging firms. Mason received his Ph.D. in economics from the University of Pittsburgh and his B.A. in economics from Geneva College.

\section{Mr. Brian Charles Dougherty, Rose-Hulman Ventures}

Brian Dougherty has spent the last 20 years working in various parts of the product development cycle. His early career focused on product design verification and manufacturing test engineering support for new products while the last 12 years has been focused on developing the new products themselves. Dougherty specializes in fast-paced development within the innovation space, and has documented how the project management practices within the innovation space should differ from classical techniques. As the Engineering Manager for Rose-Hulman Ventures, Dougherty fosters an environment where 60 engineers can develop functional proof of client concepts in a way that is more financially viable than traditional engineering firms. In addition to his managerial duties, Dougherty also acts as the lead engineer for various projects, and has most recently been leading a small team of engineers to develop ground breaking neurosurgical tools. Dougherty combines a formal education and natural creative design skills with a B.S. in electrical engineering, a M.S. in engineering management, and a lifetime of tinkering and inventing. 


\title{
Being Innovative - Lessons Learned from the Practice of Technology Commercialization
}

\begin{abstract}
Innovation has emerged as a critical priority for organizations of all types to ensure prosperity and future success. In these times of sluggish economic performance, financial austerity, and intense global competition, every organization, including higher education, needs to implement processes and a culture of innovation that deliver more value from every available resource. Engineers must be the leaders of this implementation.
\end{abstract}

Despite the attention to innovation, the philosophies and best practices of "being innovative" are still emerging. Just as the philosophies and academic discipline of leadership have emerged over the last decades, it is believed that innovation will follow the same path. Concepts will be developed from practicing innovation stage development projects and observing and recording best practices from successful outcomes.

Rose-Hulman Ventures, a technology commercialization program, is described where corporate partners bring concepts, research results, and intellectual property and teams of faculty, staff, and students develop designs, models, and prototypes as part of the commercialization process. Over ten years of operation, the program has worked with hundreds of industrial clients in a broad range of industry segments. These projects come after the research stage and fall in the critical innovation stage of development where technologies are prepared for success in the marketplace. Through these projects, several guiding principles and best practices have emerged for the process of innovation.

The paper summarizes eight "best practices" learned from these innovation-stage projects. In a broader sense, the best practices are appropriate not only for technology commercialization projects, but as guidelines of how to "be innovative" for both individuals and organizations. These eight best practices will be supported both by current literature in innovation management and the experiences of a decade of innovation and education success.

\section{Background}

The term "innovation" is widely used in a variety of contexts ${ }^{1,2,3,4}$. Innovation can take place at a variety of levels and activities including business model innovation, product and process innovation, and enabling and managing for innovation.

In this paper, we consider innovation in the context of bridging the gap between invention and commercialization. In Schoen ${ }^{5}$, invention and innovation are viewed as cyclic processes with the innovation cycle translating inventions and ideas into tangible products and services that have value to the marketplace and customers. Participants in "innovation stage" projects start with a concept, an invention, or intellectual property and the project usually lacks a detailed 
specification for development. Their challenge is to evaluate a variety of design concepts and implement the best results in timely and practical ways that make commercialization feasible.

\section{Importance of Innovation}

Innovation is emerging as a top priority for both corporate and academic organizations. In a Boston Consulting survey ${ }^{6}$ of top executives, innovation was named as a top three corporate priority by $72 \%$ of respondents. In challenging economic times, when growth in revenue is difficult to achieve, "being innovative" is critical to maximizing the returns from available resources. From an academic perspective, innovation may be essential to meet the challenges of increasing expectations and declining sources of support. For example, Christensen and Eyring ${ }^{7}$ believe that online education and the Internet are poised to disrupt many of the traditional processes of higher education.

Although the innovation process goes well beyond engineering disciplines, it is fair to say that engineers are at the heart of most of the innovation the world is seeking. The process that brings about the new products and processes includes the discovery of new knowledge and creating inventions. Arthur ${ }^{8}$ describes the term "standard engineering" as a form of expression of intention that solves problems as they arise using combinations of creativity and existing knowledge about technology. Innovating is not the application of a rigid set of rules in a disciplined process, but a much messier collection of activities that involve social organization, as well as the laws of science. The skills needed for this process are hard to reduce to traditional educational approaches and seem to require engagement with actual innovation and all of the uncertainties that entails

\section{Innovation and Educational Outcomes at Rose-Hulman}

As an institution focused on being a leader in undergraduate engineering, science, and mathematics education, Rose-Hulman is committed to providing an academic experience of the highest quality. In the $21^{\text {st }}$ century, this must include the opportunity to learn by doing. These practice experiences must provide applications of state of the art technology, demonstrations of teamwork, opportunities for leadership development, and use of processes for successful innovation. The Rose-Hulman Ventures program provides these features through high quality student internships that are supported by industrial clients seeking results that will be important for their businesses.

The Rose-Hulman Ventures (RHV) program, ${ }^{9,10}$ began in 1999 with generous Lilly Endowment funding as a unique program providing outstanding experiential learning opportunities for math, science, and engineering students. The program operates as a technology center engaging students and technology-based companies in fee for service project work that provides paid student internship experiences with the challenges and excitement of real professional practice. It offers unique benefits beyond a curriculum based approach to both the client companies and students, including realistic, cross functional views of the innovation process and the need for real deliverables. The program operates on a continuous, year-round basis with ongoing project work with 20-22 companies involving 65 students and 16 staff/faculty members working on the projects. The program impacts local economic development through the Terre Haute Innovation 
Alliance. Over 2,500 internship positions have been offered to 825 students working on a range of design, prototyping, and testing projects for over 132 client companies.

Virtually all of the projects in the program are "innovation stage" projects (as opposed to research focus) as depicted in Figure 1. The work of Schoen ${ }^{5}$ also suggests two cycles; one for invention and one for innovation, Figure 2. The projects often begin with a rough concept or intellectual property from the work done in the research or invention stage. The goals and objectives of the client project often includes the activities of design, modeling, prototyping, or testing which clearly fall in the innovation stage of advancing/enhancing a development toward commercialization and the marketplace.

\section{Methodology: The Foundation of the Lessons}

After more than a decade of experience with the "innovation stage" projects described above, the experiences of the program have shed light on the processes that bring about effective innovation. For Rose-Hulman Ventures, effectiveness has two dimensions; meeting or exceeding client expectations and educating the interns.

Established processes for technology innovation are still emerging in the literature. Conventional wisdom generally assumes that innovation follows naturally from breakthrough discoveries by creative people. Those involved in actual innovation are well aware that it is a long, difficult journey from a discovery to a useful new product or process. And that journey involves more demonstrations of creativity, as well as a hard work and learning from errors. There are well established principles of design, but innovation goes beyond those. There are many contributions from authors from different fields, but there does not appear to be an agreed upon set of best practices that work in a wide variety of contexts. In fact, Reis ${ }^{11}$ argues that resource poor firms cannot use elaborate processes that big corporations apply and must be more systematic about making efforts and analyzing feedback from them. This "doing and learning" process of innovation is very much in line with the approaches used at Rose-Hulman Ventures to both satisfy clients and prepare students for their careers. Other recent literature provides further third party verification for the conclusions drawn from the experiences at Rose-Hulman Ventures.

How does Rose-Hulman Ventures identify best practices when they are observed? One approach to revealing such things would be to collect data that can be used to statistically support or refute hypotheses about phenomena like innovation. In medicine, epidemiology generates much knowledge about practices and/or protocols and their connection to measures of mortality and morbidity. However, the notion of a population of innovation projects is difficult to imagine. Do such projects have enough similarity to meet the criteria of a statistical population, let alone representative samples of such a population? Earlier stages of the generation of new medical practices are based far more on "clinical" methodology of observing and recording information and results of specific cases. This stage of generating new practices may be based on qualitative judgments of the professionals involved. This seems to be an appropriate analogy for innovation processes at Rose-Hulman Ventures. 
The lessons that will be described below are believed to be "best practices" because they represent common themes observed in many projects and success has happened more often when they have been applied. Success in these cases is determined primarily by feedback from clients who have embraced the work done as useful for their purposes. An independent survey by Walker Information, a national firm specializing in measuring levels of customer satisfaction, found that industrial clients of the program had a higher degree of loyalty than the average for their for-profit business clients ${ }^{12}$. The other aspect of success is its benefits for students' educational outcomes. Assessment has shown that the lessons described here have led to achievement of the outcomes desired of engineering education ${ }^{9}$. There is also evidence that student participation in the program is viewed very positively by potential employers ${ }^{12}$. These lessons first appeared for a ten year anniversary celebration for the program ${ }^{13}$.

\section{A Review of the Lessons}

Within each project, there are opportunities to apply some or all of these lessons. In some cases, there is extensive support for the lessons in the literature on innovation, but other lessons are not as well known. These lessons often seem unique to the type of work being done, but they are likely to have application in a broader sense to other areas of the enterprise. For each lesson, the following paragraphs will describe the Rose-Hulman Ventures experiences, point out any literature that supports the conclusions from those experiences, and indicate any reinforcement that has been received from industrial clients.

\section{Anyone Can Play}

Innovation is a priority for all organizations and individuals and it lies within the grasp of anyone willing to make the reach. It is not a commodity or skill that can be controlled or mastered only by the wealthy or powerful - anyone and any organization can play and be successful at innovation.

RHV clients have ranged from one or two person startups to multibillion dollar corporations, and both types of organizations have been successful at innovation. They have ranged from leading edge medical device companies to a natural gas utility looking for better ways to maintain delivery lines. While some customers have deep technical expertise, others are far more dependent on the skills of the team. However, all of these organizations have been initiators and active participants in the innovation process.

This somewhat contradicts analysts like Baumo ${ }^{14}$ who argue that large firms do incremental innovation and small firms do breakthroughs. A recent paper by Mande $1^{15}$ notes that current economic conditions, including globalization, are leading to the prominence of large firms in launching innovations. Over two decades ago, Von Hippel ${ }^{16}$ found that different industries generated innovation at different stages of the value chain. For example, $77 \%$ of the major scientific instrument innovations were developed by users while $90 \%$ of the innovations in engineering plastics were by manufacturers. 
The point for engineering educators interested in entrepreneurship perspectives for students is that those students will need the basics of innovation and entrepreneurship no matter where their careers are going to take them. Innovation is not just something that $R \& D$ departments do.

Innovation is a skill and it does not require extensive training, capital investment, or facilities. It does require a mindset of being innovative with the available resources. Indeed, resource constraints are often the best motivators for innovation. Rose-Hulman Ventures has learned that input from all sources is valuable in meeting the challenges of finding a new way. Students who have not really begun their professional careers have been integral to major innovation process successes. Moreover, it is not just those with high grade point averages that are contributing. Anyone can play.

\section{It's a Team Sport}

Innovation requires the talents and contributions of many people both internal and external to your organization. A significant part of the process of being innovative is building the right team, infrastructure, and culture. These are not new conclusions, and there are many examples in the literature to support the lesson. The issues in teaming go beyond the obvious need to more specific questions of what specifically makes a group an innovative team.

A key aspect of having everyone play is the need for cross-functional teams. There is much literature highlighting the importance of getting university disciplines to collaborate. What is not so apparent, especially to engineering students, is the importance of technicians working with engineers. This has been demonstrated in a number of Rose-Hulman Ventures projects, including joint efforts with students and faculty of a local community college.

The work of Kelley ${ }^{17}$ provides several related insights to the myth of the "lone genius" and the team concept. The composition of the ideal innovation team is described and includes ten different faces or roles. These roles include not only technical skills in the required areas but also business, social, and cultural skills. In Morris ${ }^{18}$, it is noted that innovation often arises from connecting disparate perspectives and approaches. This suggests that innovation is clearly a team activity and one should intentionally seek out diversity in team members.

A unique feature of Rose-Hulman Ventures in an educational setting is that the formation and operation of the team is very much like it happens in industry. Some team members start at the beginning and leave before the work is done. Others come in the middle, and pick up someone else's work and move it toward completion. Team members are recruited for the skills they bring not their major or class standing. The team line-up is fluid, yet the different members have to learn, adapt and contribute immediately to the innovative direction.

Team members must have the ability to enter/exit an innovative project at different stages, bring particular skills and abilities, coordinate with a variety of team members, and take ownership and contribute to the project, even if it is only for a matter of weeks. 


\section{Speed Wins}

Being innovative means sometimes trying ninety-nine new things and the last trial is successful. Thomas Edison allegedly maintained that not succeeding in thousands of attempts to make a viable incandescent bulb was not failure, but learning what did not work. A priority of speed in development, prototyping, and communication allows you to "fail fast and often" to reach the successful outcomes that positively impact your organization. Furthermore, speed in getting to a prototype can mean rapid, useful feedback from customers.

Beyond the benefits to the innovation and commercialization processes, a focus on speed positively impacts organizational culture as well. A focus on speed creates a clear sense of urgency and engagement in the organization. A consequence of a focus on speed is that it may create some organizational discomfort as it may mean bypassing traditional processes of careful study, planning, and consensus building. However, those processes are based upon much more knowledge and certainty than truly innovative projects are going to have.

Notice that these comments are not about being first to market, although that can have some advantages. The goal here is to shift the approach from one of trying to anticipate and design for everything to a keep it simple, try it and learn approach. The IDEO mantra of "enlightened trial and error succeeds over the planning of the lone genius" also supports the speed in prototyping concept.

Traditional engineering education generally does not treat failure as a positive outcome. Students are generally conservative in their approaches, even to independent projects, because they need positive results for a satisfactory grade. Innovation is different. There is no way to know what you need to know to be truly disruptive for example. So it is necessary to keep trying and learning.

Extending this concept to the enterprise, the entire organization must focus on speed in all areas to really develop a culture of innovation. The technology and development teams can focus on innovation and speed, but if other groups in the organization do not, the effectiveness of the entire approach suffers. Rose-Hulman Ventures students and staff have observed this in client companies as the results of their work become successful products or are accepted, but not implemented well.

\section{Scopes Creep}

A development project typically starts with a project scope document including requirements and drawings describing the direction and destination for the proposed work. "Scope creep" or shifting direction is often characterized as evil and to be avoided at all cost. In reality, scopes do creep, issues arise, and it is rare that a project ends where you thought it would. This is particularly true for innovation. The history of innovation has countless stories of efforts that were successful with products that were different from the original idea. 
Innovation is a learning process and customers learn, too. They refine or even change their expectations as they acquire more knowledge. Moreover, the process of innovation is occurring in a dynamic environment where markets and technologies are changing before development projects can be completed. The lesson is to set a direction at the outset of a project and build in the flexibility to allow the project some latitude to follow its own course as new knowledge becomes available.

\section{Walnuts Before Peanuts}

Any prototyping or development project breaks down into a number of tasks to be completed and it is typically the case that there are a few "tough nuts" which are the difficult or challenging tasks. These may be challenges of many types including technical, packaging, usability, or manufacturability. The lesson is to prioritize tasks by expected difficulty and work on and crack the "tough nuts" first. It is easy to look over the range of challenges to be addressed and focus first on completing the many easy tasks. This often results in getting stuck on the last tough one. Solving it often means going back and revising solutions to many of the others or adopting a completely different approach to the problem.

In Schindel ${ }^{19}$, the innovation skill set is described in three dimensions of skills : discovery ${ }^{1}$, discipline, and systems engineering. In a systems approach, it is common to decompose a problem into modular functional components and address each separately. Using discipline expertise related to the development project, it is possible decompose the project into several functional components and identify the most challenging ones first.

\section{Communication is Key}

The key to tracking and controlling innovation stage projects is communication. Regular communication among team members and stakeholders is the lesson. With scopes that creep and a focus on speed, traditional project management techniques of tracking schedule and budget often are not effective. Communication in the form of email, project update reports, phone calls, and meetings will keep everyone apprised of project status. Daily or weekly frequency of communication is recommended. At Rose-Hulman Ventures, daily communication is the norm between development teams and clients. If communication frequency slows to greater than a week, this is often the sign of a troubled project.

Additional benefits of this approach are that direct communication requires close interaction between project members and getting beyond the limitations of word and experience. For example, the client or stakeholders may not know how to articulate what they really need. Or the meanings of their words can change over time; see lesson 4.

This finding aligns with the work of Hansen ${ }^{20}$ where documented systems approach for storing and communicating information is more appropriate in mature enterprises with standard products where regimented information storage is necessary. A personalized, people oriented approach is recommended for less mature or more innovative enterprises where new knowledge is created more rapidly and frequently. 


\section{Write it Down}

Innovation and being innovative is a skill and a habit. Keep a log or a journal of ideas and sketches of things to try or new ideas. Creative and innovative thoughts often come at different times and places. Write them down or sketch them out for later reflection. Sketching and concept diagrams are also a great way to document thoughts in simple forms. It would also be good to think briefly and make notes about feasibility. Timmons ${ }^{21}$ and others have pointed out that ideas alone seldom have much value. Innovation skills include being able to quickly think through execution issues and evaluate potential. Since ideas can be plentiful, it is good to at least quickly consider and write down obstacles, as well as promise. At the same time, this is not to say that difficulties should cause ideas to be forgotten. Morris ${ }^{18}$ has noted that innovation is often the result of combinations of information from disparate sources. Good innovation processes need to document and collect thoughts in ways that facilitate retrieval and application when needed.

\section{Lead from the Side}

A traditional top-down management style of the authoritative boss giving direction does not create a culture of innovation. Lead from the side and give your co-workers the confidence and resources to step up and try new ideas and build a culture of innovation. This framework for thinking about how to lead grew out of the experiences of both trying to innovate and trying to provide students with skills that would make them innovators. The faculty and project engineers at Rose-Hulman Ventures provide clear leadership yet position themselves to encourage the student team to produce as much as possible with guidance when needed and also intervene to prevent catastrophic mistakes. Students within the teams are encouraged to operate the same way with the other students. They are to step forward when they can contribute to the success of the team. Innovation often requires leadership to change from person to person depending upon the context of the problems that must be solved.

Students observe the leading from the side by the project engineers and faculty mentors and have those observations reinforced by events, activities and speakers that address the importance of collaboration to get results. Students learn that assuming leadership when their skills are needed is not about seizing power or a superior position, but facilitating the path of the team through the situation.

The entrepreneurship and innovation literature includes many words of advice about leadership, but thinking about it in this positional way is not apparent in the discussions. Allen $^{22}$, for example, describes leadership traps that include leader isolation from the team, the need to have the "right answer" and not building support. Byers ${ }^{23}$ says that "leadership is the process of influencing and motivating people to work together to achieve a common goal by helping them secure the knowledge, power, tools, and processes to do so." It is also suggested that the leader "can be thought of as a leader of a jazz band". This seems aligned with the positioning being discussed here. However, the lesson here is that the place of the leader should be explicit, especially to those who are trying to provide leadership.

This leading from the side approach also explicitly addresses some emerging thinking about the nature of entrepreneurial behavior and advancements in technology. Historically, the 
typical approaches to innovation seem to be founded on the use of knowledge to predict outcomes and then to use those predictions to guide the development process. That is, innovation uses causal logic to guide decisions. Recently, a new model from Sarasvathy ${ }^{24}$ suggests says that the future of a business or technology cannot be predicted and that entrepreneurs operate using a logic of controlling the situations as the future unfolds. The hypotheses following from this shift in theory have found support in studies of the behavior of "expert entrepreneurs", see Duening ${ }^{25}$. It suggests that the traditional idea that the leader should provide direction based upon superior knowledge does not apply. Instead, the team should be learning to control phenomena arising during the innovation process. This is consistent with the earlier lessons about the team and the scope. It is also connected to the recent work of Arthur $^{8}$ on the nature of technology and its advances as a "messy vitality" that combines lots of existing known technologies, rather than a process to discover the pure order of things.

\section{Conclusions for Education and Further Investigation}

A collection of eight best practices for innovation in technology development projects have been presented. These results provide guidance for not only development and prototyping projects but also serve as motivating themes for innovation at higher levels of the enterprise. For undergraduate engineering, math, and science education, the message is clear that innovation skills must be taught to our graduates. These skills will be a requirement for success in the workplace of the future. Innovation is also a priority for colleges and universities to develop new operating approaches to adapt to the challenges of rising costs and declining support.

While these practices have been observed and captured as best-practices, more work is needed to systematically verify that these best practices are common across a broader range of experiences. This will require the reduction of these practices to brief phrases that can be used reliably in surveys of both clients and students to get perceptions of their presence in projects. Data on the presence of best practices will then be compared to the measures of client satisfaction that determine project success. Efforts will also be made to categorize projects to determine if the lessons are indeed universally valuable. Such measures will be important for further validating the lessons offered here. They will also provide the basis of a quality system for Rose-Hulman Ventures. Ultimately, Rose-Hulman and other institutions can find ways to incorporate these lessons within the curriculum so that the schools are themselves innovative and graduating leaders for the innovation processes of the future. Feedback from engineering education colleagues on the lessons framed here will be crucial in attaining that goal. 


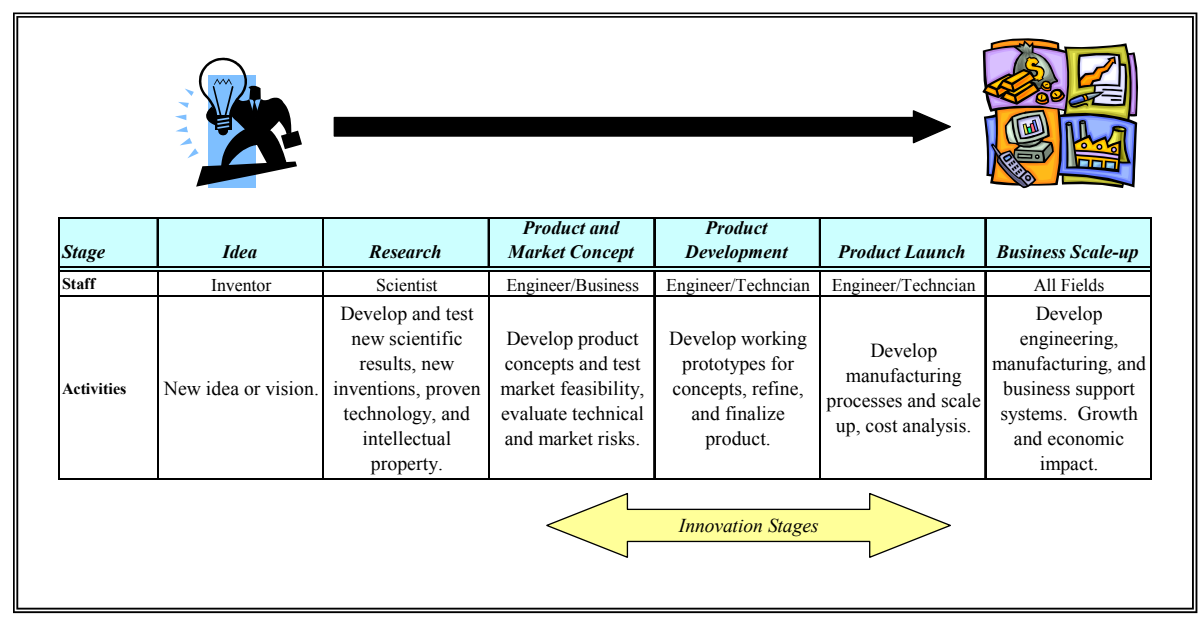

Figure 1 - Linear Invention to Innovation Model $^{10}$

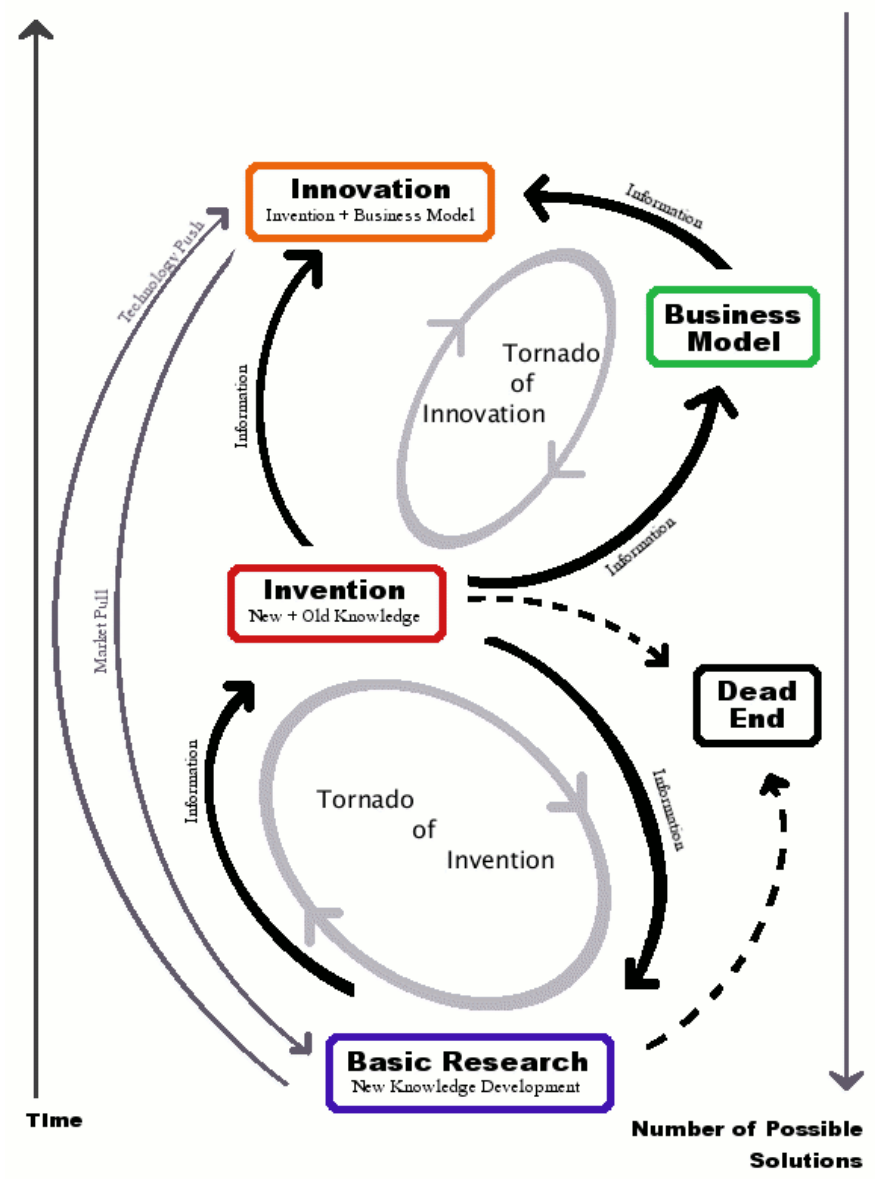

Figure 2 - Schoen $^{5}$ Innovation Cycle Model 


\section{References}

1. Dyer, Jeff, Hal Gregerson, and Clayton M. Christensen. The Innovator's DNA. Boston: Harvard Business Review Press, 2011.

2. "How Companies Approach Innovation: A McKinsey Global Survey," The McKinsey Quarterly. 2007.

3. Johnson, Mark W. Seizing the White Space. Boston: Harvard Business Press, 2010.

4. Jakubowski, J, A. Western, and W. Kline. "The Innovation University.” Proceedings of ICEE/ICEER Conference. Korea, August 2009.

5. Schoen, Jeremy, Thomas W. Mason, William A. Kline, and Robert M. Bunch. "The Innovation Cycle: A New Model and Case Study for the Invention to Innovation Process." Engineering Management Journal. Vol. 17, No. 3, September 2005.

6. Andrew, James P., Joe Manget, David Michael, and Hadi Zablit. "Innovation 2010, A Return to Prominence.” Boston Consulting Group, April 2010.

7. Christensen, Clayton M. and Henry Eyring. The Innovative University: Changing the DNA of Higher Education from the Inside Out. San Francisco: Jossey-Bass, 2011.

8. Arthur, W. Brian. The Nature of Technology: What It Is and How it Evolves. New York: Free Press, 2009.

9. Kline, William A. and Thomas Mason. "Rose-Hulman Ventures, Outcomes from an Experiential Learning Program." Proceedings of the 2007 Midwest Section Conference of the American Society for Engineering Education. September 2007.

10. Kline, William A. and Thomas Mason. "Innovation Stage Projects for Undergraduate Engineers, Defining Mission Through a Focus on Innovation." Proceedings of the 2009 American Society of Engineering Education IL/IN Section Conference. Valparaiso, IN, March 2009.

11. Reis, Eric. The Lean Startup: How Today's Entrepreneurs Use Continuous Innovation to Create Radically Successful Businesses. New York: Crown Business, 2011.

12. Walker Information, Inc., Rose-Hulman Ventures Client Assessment, December, 2008. Details available by request from the authors.

13. Decade of Innovation. Rose-Hulman, February 27, 2010. www.decadeofinnovation.com/secrets.php.

14. Baumol, William. The Microtheory of Innovative Entrepreneurship. Princeton: Princeton University Press, 2010.

15. Mandel, Michael. "Scale and Innovation in Today's Economy". Progressive Policy Institute (http://progressivepolicy.org/scale-and-innovation-in-todays-economy), December 7, 2011. cited in "Schumpeter - Big and Clever", The Economist. December 17 -30, 2011, p.116. 
16. Von Hippel, Eric. The Sources of Innovation. New York: Oxford, 1988.

17. Kelley, Tom and Jonathan Littman. The Ten Faces of Innovation. New York, Currency Doubleday, 2005.

18. Morris, Langdon. The Innovation Master Plan. Innovation Academy, 2011.

19. Schindel, William D., Samuel N. Peffers, James H. Hanson, Jameel Ahmed, and William A. Kline. "All Innovation is Innovation of Systems: An Integrated 3-D Model of Innovation Competencies." Proceedings of the 2011 ASEE Annual Conference. Vancouver, Canada, July 2011.

20. Hansen, Morton T., Nitin Nohira, and Thomas Tierney. "What's Your Strategy for Managing Knowledge." Harvard Business Review. March-April 1999.

21. Timmons, Jeffrey A., Andrew Zacharakis, and Stephen Spinelli. Business Plans that Work. New York: McGraw Hill, 2004.

22. Allen, Kathleen. Launching New Ventures. Boston: Houghton Mifflin, 2009. P.284.

23. Byers, Thomas H., Richard C. Dorf, and Andrew J. Nelson. Technology Ventures: From Idea to Enterprise. New York: McGraw Hill, 2011.

24. Sarasvathy, Saras D. "Causation and Effectuation: Toward a Theoretical Shift from Economic Inevitability to Entrepreneurial Contingency.” Academy of Management Review. Vol. 26 Issue 2, April, 2001, pp.243-263.

25. Duening, Thomas N., Robert D. Hisrich, and Michael A. Lechter. Technology Entrepreneurship: Creating, Capturing and Protecting Value. Burlington, MA: Academic Press, 2010. 